\title{
Cryoglobulinemic glomerulonephritis - lessons from animal models
}

\author{
Jolanta Kowalewska
}

Department of Medical Pathomorphology, Medical University of Bialystok, Poland

\begin{abstract}
In humans cryoglobulinemic glomerulonephritis (CGGN) may develop in the course of systemic cryoglobulinemia (CG) and is often associated with hepatitis $\mathrm{C}$ virus infection. It is believed that the glomerular injury in CG results from the deposition of immune complexes, but exact sequence of events in this process is unknown. Experimental models of CGGN provide an important tool to study pathogenesis of this type injury. This review describes two mouse models of CGGN and their use in understanding the role of various molecules involved in regulation of inflammatory and fibrosis pathways, such as complement components, Fc receptors, growth factors, and others; as well as illustrates their role in testing novel approaches of treatment in this type of renal injury. (Folia Histochemica et Cytobiologica 2011; Vol. 49, No. 4, pp. 537-546)
\end{abstract}

Key words: cryoglobulinemia, glomerulonephritis, animal models

\section{Cryoglobulinemic glomerulonephritis}

Cryoglobulinemic glomerulonephritis (CGGN) is a type of membranoproliferative glomerulonephritis (MPGN) that develops in the course of systemic cryoglobulinemia (CG). Glomeruli in MPGN are hypercellular with accentuated lobular architecture due to mesangial and endothelial cell proliferation and influx of leukocytes, mainly monocytes and macrophages. Areas of mesangiolysis may be present. Glomerular capillary walls are irregularly thickened due to endothelial cell swelling, accumulation of subendothelial immune complexes (IC), or duplication or remodeling of capillary basement membranes. Sometimes accumulation of luminal precipitated IC may be seen in the capillary lumina as a PAS positive globular material (Figure 1). On immunofluorescence (IF) examination these complexes are composed of immunoglobulin (Ig) IgM and/or IgG, with or without light chain restriction, and complement

\footnotetext{
Correspondence address: J. Kowalewska, Department of Medical Pathomorphology, Medical University of Bialystok, Waszyngtona Str. 13, 15-269 Bialystok, Poland; tel.: (+ 48 85) 74859 45, fax: (+ 48 85) 74859 90; e-mail: jolanta.kowalewska@umb.edu.pl
}

fragment C3 (Figure 2). Ultrastucturally, the IC, visible as electron dense deposits, are located in subendothelial, but also in luminal and mesangial location, and in approximately $30 \%$ of cases have organized appearance in forms of fibrils or tactoids. The classical cryoglobulins (CGs) appear as well organized tubules with $>30 \mathrm{~nm}$ in diameter and central hole (Figure 3).

The exact mechanisms leading to such injury still remain unknown; therefore having an animal model of this type of glomerular disease is invaluable. This review focuses on the CG associated GN, briefly describes available experimental animal models of CGGN, and discusses the insides into pathogenesis and treatment options based on the observation made using these models.

\section{Cryoglobulinemia}

The term cryoglobulinemia refers to the presence of circulating Igs in a patient's serum that precipitate in temperatures lower than $37^{\circ} \mathrm{C}$. The first description of this type of precipitation, termed cryoprecipitation, has been attributed to Wintrobe and Buell, who in 1933 described a patient with symptoms of hyperviscosity associated with multiple myeloma (MM) [1]. In 1947, the term "cryoglobulin" was applied to this 


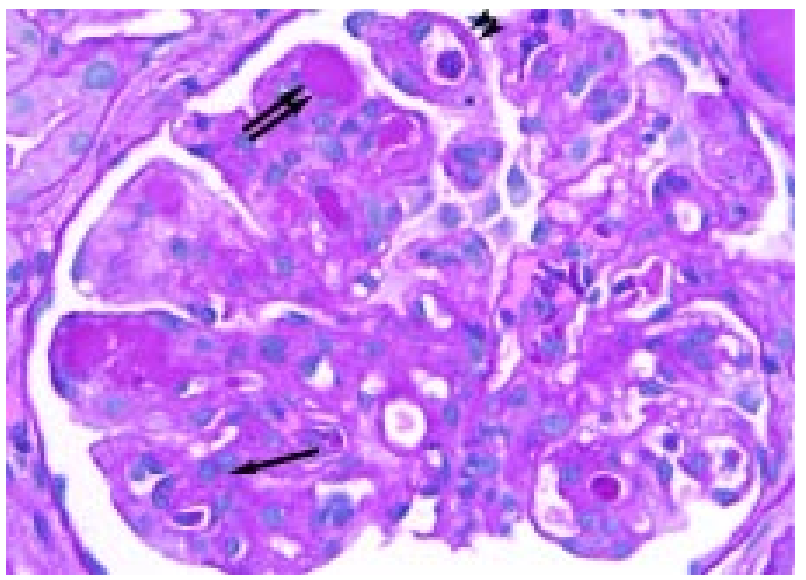

Figure 1. Cryoglobulinemic glomerulonephritis. Mesangial hypercellularity (arrow), double contour of capillary basement membrane (arrowheads) and intracapillary immune complexes (double arrows). (PAS, original magnification $\times 400$ )

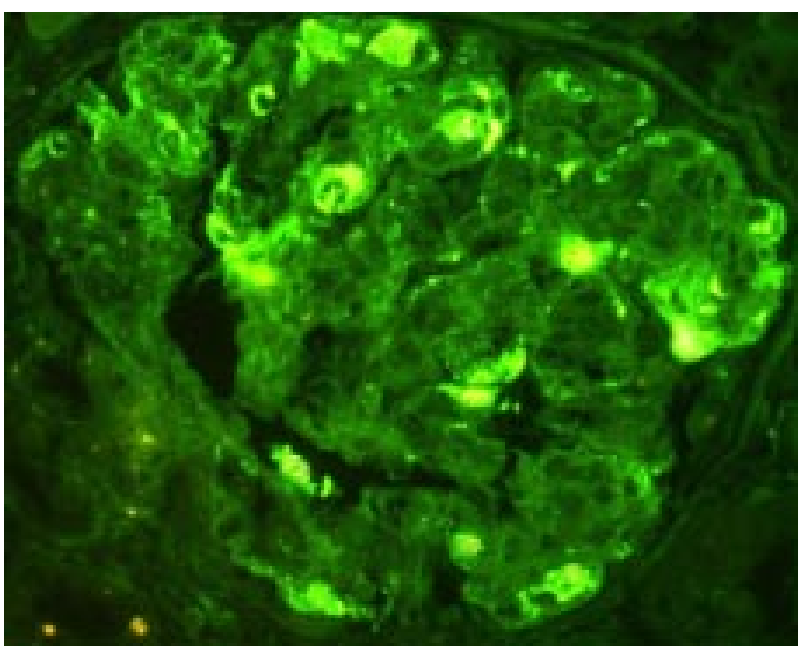

Figure 2. Cryoglobulinemic glomerulonephritis. Intense immunofluorescence staining highlighting IgG deposits in mesangial areas, glomerular capillary walls, and within luminal spaces. $(\mathrm{IgG}$, original magnification $\times 400)$

"cold precipitable serum globulin" [2]. The presence of these Igs has been associated with variety of clinical symptoms including, but not limited to, hyperviscosity [1], triad of palpable purpura, arthralgia and myalgia - "Meltzer's triad" [3, 4], and glomerulonephritis [5]. Hyperviscosity is typically associated with CG due to hematological malignancies and monoclonal Igs, while the Melzer's triad is generally seen in association with polyclonal CGs seen in essential-, viral-, or connective tissue disease-associated CG.

The prevalence of clinically significant CG has been estimated at approximately 1:100,000, although detectable levels of circulating CGs have been seen in a significant proportion of patients with chronic infections and/or inflammation: 15 to 20 percent in

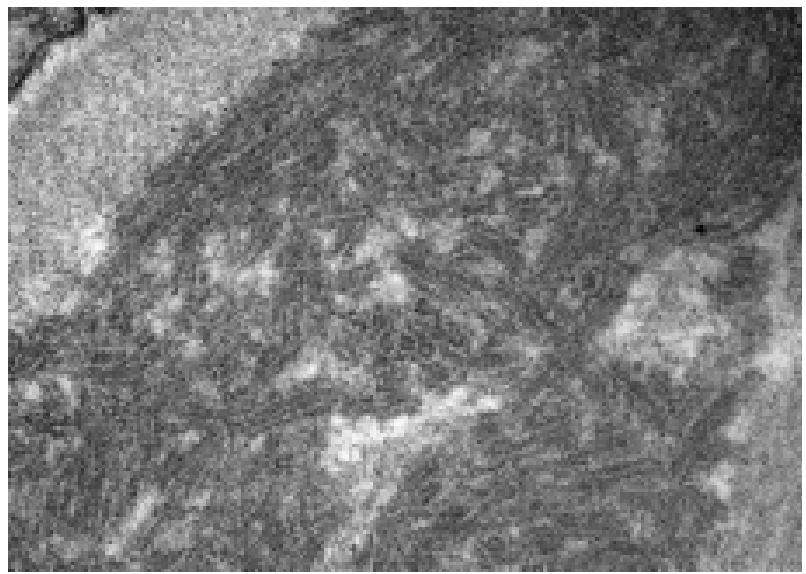

Figure 3. Cryoglobulinemic glomerulonephritis. Cryoglobulins in subendothelial space organized as slightly curved microtubular structures. (Transmisson electron microscopy, original magnification $\times 69,000)$

HIV infection, 15 to 25 percent in connective tissue diseases, 40 to 65 percent in hepatitis $\mathrm{C}$ virus (HCV) infected individuals, and as high as 64 percent in HIV and hepatitis $C$ coinfection [6-10]. Other infectious agents proposed, but not proven, to have an association with $\mathrm{CG}$ include hepatitis $\mathrm{B}$, cytomegalovirus, Epstein-Barr virus and human parvovirus B19 [11].

With the discovery of HCV a considerable attention has been paid to the role of this virus in the pathogenesis of number of cases (in some series more than 90\%) of previously considered as essential CG [12-14]. According to WHO as many as 170 million people around the world are infected with HCV (an overall incidence of around 3\% of the world's population; http://www.who.int/mediacentre/factsheets/fs164/en/ June 2011), and while liver disease is a main consequence of this infection, the extra hepatic manifestations of such infection include mixed CG and kidney injury. In the course of HCV infection patients may develop glomerular disease such as membranous glomerulopathy or focal segmental glomerulosclerosis, but the strongest association is that with MPGN.

\section{Nature of cryoglobulins}

CGs are either monoclonal or polyclonal Igs or a mixture of Igs and complement components. The routine laboratory test for detection of CG is based on cooling the patient's serum. For the test to be properly done the blood should be drawn into prewarmed to $37^{\circ} \mathrm{C}$ syringes and/or collection tubes without anticoagulants (anticoagulants may produce falsely positive results through the formation of cryofibrinogen or heparin-precipitable complexes) and delivered to the laboratory warm. After clotting at $37^{\circ} \mathrm{C}$, separated serum should be subsequently cooled in $4^{\circ} \mathrm{C}$ to al- 
Table 1. Classification of cryoglobulinemia

\begin{tabular}{|l|l|l|l|}
\hline & Type I & Type II mixed CG & Type III mixed CG \\
\hline Composition & $\begin{array}{l}\text { Single monoclonal Ig mainly IgG, } \\
\text { IgM, or IgA, or monoclonal free } \\
\text { light chains }\end{array}$ & $\begin{array}{l}\text { Presence of monoclonal component: } \\
\text { usually IgM, IgG, } \\
\text { or IgA and polyclonal Ig (mainly IgG) }\end{array}$ & Polyclonal mixed Ig \\
\hline $\begin{array}{l}\text { Biological } \\
\text { characteristics }\end{array}$ & $\begin{array}{l}\text { Self-aggregation through } \\
\text { Fc fragment of Ig }\end{array}$ & $\begin{array}{l}\text { RF activity of monoclonal component } \\
\text { against Fc portion of polyclonal Ig } \\
\text { predominant }\end{array}$ & $\begin{array}{l}\text { RF activity of one polyclonal } \\
\text { component (usually IgM) }\end{array}$ \\
\hline $\begin{array}{l}\text { Clinical } \\
\text { associations }\end{array}$ & $\begin{array}{l}\text { Lymphoproliferative disorders: } \\
\text { multiple myeloma, Waldenstrom's } \\
\text { macroglobulinaemia, chronic } \\
\text { lymphocytic leukemia, B cell NHL }\end{array}$ & $\begin{array}{l}\text { Viral, bacterial, parasitic infections } \\
\text { (mainly HCV, less HBV, others), } \\
\text { autoimmune diseases, lymphopro- } \\
\text { liferative disorders rare }\end{array}$ & $\begin{array}{l}\text { Viral, bacterial, parasitic infections } \\
\text { (mainly HCV, less HBV, others), } \\
\text { autoimmune diseases, lymphopro- } \\
\text { liferative disorders rare }\end{array}$ \\
\hline
\end{tabular}

CG — cryoglobulinemia; Ig — immunoglobulin; RF — rheumatoid factor; NHL — non-Hodgkin's lymphoma; HBV — hepatitis B virus; $\mathrm{HCV}$ - hepatitis C virus

low the precipitation of CG [15]. A cryocrit is determined by measuring the packed volume of the precipitate as a percentage of the original serum volume at $4^{\circ} \mathrm{C}$.

\section{Classification of cryoglobulinemia}

Based on the molecular composition the CGs has been divided into three types (Table 1) [16, 17]. Type I is characterized by the presence of isolated monoclonal Ig (typically IgG or IgM, less commonly IgA or free immunoglobulin light chains). According to various case series the proportion of patients with a Type I CG varies between 5 and 25 percent of cases. It is most commonly associated with hematologic abnormalities, such as Waldenström's macroglobulinemia and MM. Type II CG, which is also called essential mixed cryoglobulinemia, the Igs are composed of mixture of polyclonal and monoclonal Ig, typically IgM, IgG or IgA, with rheumatoid factor activity. This type of CG accounts for approximately 40 to 60 percent of cases and has been seen in association with chronic viral infections, most commonly $\mathrm{HCV}$ and HIV infections. In type III CG, the CGs consist of polyclonal Igs and are seen in approximately 25 to 30 percent of all patients with CG. Type III CG is most often observed as a secondary phenomenon to connective tissue diseases). While this classificaton is generally useful, it does not account for atypical forms of CGs, such those with oligoclonal IgM components with or without trace polyclonal immunoglobulin responses, often referred to as type II-III, or biclonal CGs [18]. Updated classifications are being developed to address specific components of cryoglobulinemic syndrome such as cryoglobulinemic vasculitis [19].

The pathogenesis of CG is still not completely understood. While small amount of CGs can be detected in the serum of healthy persons, many investigators have proposed that their presence reflects the ongoing physiological clearance of endogenous immune complexes by immunoglobulins with rheumatoid factor activity. It appears then, that an abnormal immunological response may result in production of excessive amount of CGs, which may become pathogenic. Number of factors has been proposed to elicit such responses, including: production of higher concentrations of mono-, oligo-, or polyclonal CG as a result of chronic immune stimulation and/or lymphoproliferation, formation of potentially pathogenic immune complexes, and their defective or insufficient clearance.

\section{Animal models of cryoglobulinemia}

There is a number of experimental models of MPGN that have been recently reviewed by Vernon et al. [20]. These include sponaneous type I MPGN associated with C3 deficiency described in dogs, lambs, horse and pigs, and factor $\mathrm{H}$ deficient pig. Glomerulonephritis resembling dense deposist disease (previously known as MPGN type II) has been observed in pigs with a genetic deficiency of the complement control protein factor $\mathrm{H}$. Some of these models have limited utility as a generalized animal models due to their large size, high cost of care, and a lack of specific reagents for these species. This article focuses primarly on engeenired murine models of MPGN associated with CG.

Thymic stromal lymphopoetin (TSLP) is a thymus derived 140-amino acid protein that supports differentiation of IgM-positive B lymphocytes and promotes mitogenic activity of fetal thymocytes [21, 22]. Overexpression of TSLP in mice results in development of cryoglobulinemia with its systemic consequences of widespread inflammatory disease involving skin, liver, lungs, kidneys and spleen [23]. The CG is of mixed type (type III), similar to that developed in humans in the course of HCV infection. These mice consistently develop glomerular disease in form of 
MPGN that closely resembles that seen in humans. The development of the glomerular disease has a highly predictable course, making this animal model suitable for experimental studies of CG-associated MPGN. The development of GN in these mice is accompanied by a statistically significant increase in albumin excretion and a small increase in blood urea nitrogen compared to their wild type (WT) littermates. The liver involvement mimics the disease seen in patients infected with $\mathrm{HCV}$ [24], therefore it may potentially serve as a valuable model to study liver injury associated with $\mathrm{HCV}$ and CG. Most of the mice develop ulcerated skin lesions predominately located on the ears and tails (cold areas). Histologically, these lesions are characterized by the presence of vasculitis. Lungs are often heavily infiltrated by inflammatory cells, mainly eosinophils and crystal containing macrophages, that fill the pulmonary alveoli, and likely contribute to the animal death.

The glomerular involvement in this model is characterized by a membranoproliferative pattern of injury, including lobular accentuation of the tuft, increased glomerular size, an absolute increase in the cell number per glomerulus, and increase of extracellular mesangial matrix [23]. The inflammatory infiltrate of the glomeruli is mostly composed of macrophages. There is glomerular deposition of immune complexes, composed of polyclonal $\mathrm{IgM}$, IgG, less often $\operatorname{IgA}$, and complement component C3. Ultrastructural examination reveals immune type deposits in mesangial areas and in subendothelial locations of capillary walls, sometimes associated with duplication of glomerular basement membrane. In many cases the immune deposits are organized in the form of microtubules arranged in arrays, similar to that seen in humans.

The second animal model of CGGN is induced by an infusion of murine hybridoma cells producing monoclonal IgG3, which behaves as CG [25]. This model was further improved by the development of mice overexpressing IgG3 with both, rheumatoid factor and cryoglobulin activity [26]. These mice develop cutaneous leukocytoclastic vasculitis and glomerular injury. The glomerular lesions are heterogeneous, including membranoproliferative type of injury, crescents, and sclerosis; in addition, one-third of animals develop necrotizing arteritis in the kidneys and skeletal muscles. The glomerular inflammatory cell infiltration in this model is composed predominately of polymorphonuclear leukocytes (which is different than that in TSLP tg mice composed mainly of macrophages). The glomeruli exhibit extensive, confluent, wire-loop-like subendothelial deposits composed mainly of IgG3 and C3, and occasionally of IgG2a. In some glomeruli these deposits appear to be luminal and are obstructing the glomerular capillary lumina.

\section{Pathogenesis - insights from animal models}

It is believed that the glomerular injury in CG results from the deposition of immune complexes, which in turn lead to release of growth factors and inflammatory mediators and recruitment of inflammatory cells. While the exact sequence of events in such injury is unknown, experimental models of MPGN provide new insights into the pathogenesis of this injury.

\section{Type of immunoglobulins}

The IgG3 isotype of Ig has a unique property to form self-associating complexes as a result of nonspecific IgG3 Fc-Fc interaction [27]. This phenomenon is likely to be responsible for the cryoglobulin activity observed with some IgG3 myeloma proteins in humans [28] and a majority of IgG3 in mice [29]. Significantly, the implantation of hybridoma cells secreting IgG3 anti-IgG2a RF rapidly induces murine acute glomerulonephritis and cutaneous leukocytoclastic vasculitis, further confirming pathogenic activity of IgG3 cryoglobulins. Additionally, this model provides a proof that while RF and CG activity are required for development of skin lesions, the anti-IgG2a RF activity is not necessary for development of glomerular lesions [26].

\section{Complement and Fc receptors}

There are two major mechanisms of triggering inflammatory responses by immune complexes: by activation of complement cascade [30] and via the engagement of cellular receptors for $\operatorname{IgG}$ (Fcg receptors, FcgR) [31]. The complement system contains three activation pathways (classical, alternative and lectin) along with numerous regulators at key points throughout. The immunoglobulins activate classical complement cascade by binding to the complement factor $\mathrm{C} 1 \mathrm{q}$, that leads to the production of several chemoreactants, among them C3a and C5a, and subsequently to the formation of the membrane attack complex C5b-9 (MAC). MAC has lytic and activatory activity that may lead to cellular injury or activation with subsequent release of inflammatory mediators. While in the normal situation the complement system serves as a part of the host defense mechanism, its prolong/ /improper activation may lead to the undesirable cellular injury. There are several mechanisms that regulate the complement cascade in order to prevent such disastrous results. 
Crry is a membrane bound protein with complement inhibiting properties, which represents the rodent functional analog for human decay accelerating factor (DAF) and membrane cofactor protein (PCP). It blocks complement activation at the level of $\mathrm{C} 3$ convertase leading to the inhibition of the classic and alternative pathways [32]. Overexpression of Crry has been shown to be protective in some forms of complement-mediated injury in vitro [33] and in vivo [33-36].

In TSLPtg mouse model of CR-MPGN the overexpression of Crry did not result in significant improvement of renal pathology, laboratory findings, or the formation of the MAC [37]. It possible that the failure of Crry to protect these mice from glomerulonephritis result from several possibilities, including, but not limited to: the overwhelming action of chronic complement activation is too potent for the inhibitory activity of Crry, the lack of efficacy of complement inhibition, or a possibility that the complement may have a protective role in the pathophysiology of the disease by promoting of disposal of immune complexes.

The role of complement was also investigated in mice with cryoglobulinemia induced by injection of hybridoma cells [38]. Two strains of mice (C57BL/6 and $\mathrm{BALB} / \mathrm{c}$ ) were made deficient in various complement components, such as $\mathrm{C} 3$, factor $\mathrm{B}$, and $\mathrm{C} 5$, to test the role of alternative pathway of complement activation, and $\mathrm{C} 1 \mathrm{q}$ to test the role of classical pathway. The cryoglobulins produced by mice with $\mathrm{BALB} / \mathrm{c}$ background have both CG and RF activity while the cryoglobulins produced by mice on c57BL/ 6 background are composed of IgG3 with cryoglobulin activity only. No difference in the role of complement was found between the two strains, and no survival advantage was found when the mice were made complement deficient. Glomerular injury, measured as influx of neutrophils was ameliorated in $\mathrm{C} 3$, factor B and $\mathrm{C} 5$-deficient mice compared to C1q-deficient mice, pointing to important role of the alternative pathway of complement activation in this type of injury. Also, by testing for the role of CD59a - the membrane inhibitor of MAC, the authors of this study [38] found that the lack of CD59 did not worsen the influx of neutrophils, therefore they concluded that C5a may be responsible for influx of leukocyte. This observation leads to the conclusion that possibly C5 blockade may be a potential therapeutic strategy for amelioration of kidney injury in CGGN.

A prominent role for the mediation of disease is the engagement and activation of $F c$ receptors (FcRs) on leukocytes by the Fc portions of immunoglobulins that are present in the immune complex- es. Mice possess four well-studied classes of FcRs, which depending of their intracytoplasmic domains have either activating or inhibitory effects. The activating receptors include FcgammaRI (FcgRI), FcgRIII and FcgRIV. Engagement of activating receptors Fcgs results in proinflammatory activities, such as mobilization of calcium, degranulation and release of cytokines. Activation of the inhibitory receptor FcgIIb results in inhibition of the proinflammatory processes [39].

The importance of the inhibitory role of the FcgRIIb was proved in TSLPtg mice [40]. In these animals the genetic deletion of FcgRIIb resulted in the exacerbation of MPGN as shown by the worse kidney function and aggravated glomerular pathology with increase in extacellular matrix, mesangial hypercellularity and influx of macrophages [40]. However, the deletion of the activating Fcg receptors in TSLPtg mice did not provide expected protection from the cryoglobulinemia related MPGN [41]. The renal disease in TSLPtg mice with deleted activating FcgRs was compatible to that seen in TSLPtg mice with intact receptor. Moreover these mice had higher levels of cryoglobulinemia and more immune complexes in the glomeruli [41]. It appears from this study that the Fcgs may play an important role in the clearance of immune complexes both from the circulation and the deposits in the tissue.

\section{Growth factors and other regulators of renal fibrosing injury}

Production and deposition extracellular matrix (ECM) leading to glomerulosclerosis and interstitial fibrosis is one of the features of progressive, often irreversible renal injury. Studies have shown that platelet-derived growth factor (PDGF) and transforming growth factor (TGF- $\beta$ ) play an important role in mesangial cell proliferation and deposition of ECM [42-46]. Recently, van Roeyen et al. [47] showed that podocyte specific overexpression of PDGF-D in mice causes mesangioproliferative disease, glomerulosclerosis, and crescentic glomerulonephritis.

In the TSLP tg mice model of CGGN there is a prominent induction of PDGF-B chain and corresponding PDGF- $\beta$ receptor (-R) that parallels mesangial matrix expansion and mesangial cell proliferation. The expression of both the ligand and the receptor is present in mesangial cells and parietal epithelial cells. In contrast, the expression of PDGF-A chain and its receptor PDGF-alfa- $\mathrm{R}$ is only limited or absent [48].

TGF- $\beta$ is another growth factor thought to play an important role in mesangial matrix expansion. This factor is probably produced along the pathway of 
ECM production following stimulation of immune complexes via Fc receptors. Indeed, in the TSLP tg mice a significantly higher level of glomerular TGF- $\beta$ mRNA expression was noted when compared to that in wild type littermates. These observations confirm further a significant role of PDGF and TGF- $\beta$ in the mesangial injury and repair. Further studies aimed at interrupting their pathways might serve as a useful models system to test therapeutic interventions in this type of glomerular injury.

Another potent regulators of accumulation of ECM leading to glomerulosclerosis and interstitial fibrosis are activators and inhibitors of plasmin [49-51]. Plasmin is a key enzyme involved in degradation of components of ECM and fibrinolysis in coagulation pathway, and it is believed to have a major role in regulation of renal fibrosing injury. Plasminogen activators (PA), such as tissue plasminogen activator (tPA), are serine proteases that convert plasminogen into plasmin, thus enhancing deradation of EMC. Number of plasminogen activator inhibitors, such as protease nexin-1 (PN-1) and plasminogen activators inhibitor PAI-1, among their complex activities, they inhibit generation of plasmin. Several studies demonstrated decreased PA activity and plasmin activity in glomeruli in various forms of experimental injury that resulted in mesangial matrix expansion $[52,53]$. Increased levels of PAI-1 have been observed in various forms of kidney diseases leading to renal fibrosis $[53,54]$. Upregulation of PN-1 has been shown in number of experimental models of immune-mediated glomerulonephritis [55].

The microarray studies of TSLP tg mice showed a significant upregulation of PN-1 and tPA compared to WT animals [56]. This observation was further confirmed by in situ hybridization that revealed the same results. Also, immunochemical studies revealed increased expression of PN-1, tPA, and PAI-1 in messangial cells of TSLP tg animals. The role of CG in mediation of this cellular response was subsequently showed in cultured mesangial cells, which after incubation with $\mathrm{CGs}$ showed upregulation of PN-1 mRNA, increased expression of PN-1, tPA, and PAI-1 proteins, and increased secretion of profibrotic TGF- $\beta 1$. The authors of this study concluded that PN-1, tPA, PAI- 1 and TGF- $\beta 1$ are likely to be important mediators of glomerular injury in murine CGGN.

\section{Role of macrophages}

Monocytes/macrophages are heterogeneous population of cells that play important role in inflammation, phagocytosis, repair, and tissue remodeling [57, 58]. These cells are often present in various forms of glomerulonephritis, although it is still unknown whether they are effectors of the injury and glomerulosclerosis or they play beneficial role in the repair of glomerular injury. In experimental settings it is possible to eliminate or markedly reduce infiltration of macrophages to test such questions. This has been achieved by creation of an unique stain of transgenic mice (CD11b-DTR tg) in which human Diphteria toxin receptor (DTR) is specifically expressed by monocyte/macrophage-restricted promotor CD11b. In these animals administration of DT results in conditional ablation of monocyte/macrophages lineage of cells [59].

Mice made doubly transgenic for TSLP and CD11b-DTR develop (after administration of DT) systemic cryoglobulinemia and glomerular deposition of immune complexes similar to that seen in TSLP tg animals, but the glomerular infiltration of macrophages in these animals is markedly reduced [60]. The decreased number of glomerular macrophages results in significant reduction in structural (reduced matrix and collagen IV accumulation, decreased mesangial cell activation, and lower expression of TGF-b1) and functional (decreased proteinuria) glomerular injury. It appears then that in this model of experimental CGGN the macrophages have predominately harmful role in the mediation of glomerular injury.

\section{Cryoglobulinemic glomerulonephritis (CGGN)}

\section{Pathogenesis - key points}

- Rheumatoid factor activity of immunoglobulins, while required for development of skin lesions, might not be necessary for development of glomerular lesion in murine CGGN.

- Inhibitory activity of Crry is not potent enough to protect cryoglobulinemic mice from development of glomerulonephritis.

- Isolated deficiency in complement cascade components, such as $\mathrm{C} 3$, factor $\mathrm{B}, \mathrm{C} 5$, or $\mathrm{C} 1 \mathrm{q}$, does not provide survival benefit in murine CGGN.

- C5a may be responsible for influx of leukocytes in CGGN.

- Deletion of inhibitory FcgRIIb aggravates murine CGGN, while deletion of activating FcgR does not provide protection against development of glomerulonephritis.

- PDGF-B and TGF- $\beta$ play significant role of in the mesangial injury and repair in CGCN.

- PN-1, tPA, and PAI-1 are important mediators of glomerular injury in murine CGGN.

- Macrophages are essential contributors to kidney injury in murine CGGN. 


\section{Treatment}

The treatment of CG varies depending on the underlying disease state. In the absence of well-delineated, evidence-based guidelines, most clinicians emphasize the importance of management directed toward the underlying diseases, such as plasma cell disorder, chronic infection, etc.

Depending of the severity of the symptoms the treatment ranges from conservative therapy, such as avoidance of cold, to use of analgesics and nonsteroidal antiinflammatory drugs (NSAIDs). More potent immunosuppressive or immunomodulatory therapy, such as steroids, plasmapheresis, and cytotoxic agents, are reserved for organ-threatening or refractory disease.

The animal models of CG provide an excellent tool for testing new approaches in the modulation and potential treatment of the disease. Based on the findings in the genetically modified animals, new tactics toward the treatment of CG and CGGN has been proposed.

\section{PDGF inhibition}

As discussed earlier, the demonstration and presumptive role of PDGF-B chain and its receptor and TGF- $\beta 1$ in the TSLP tg mice model of MPGN provided useful hope for a potential treatment of this form of glomerulonephritis. To date one of such approaches has been tested aimed at the inhibition of PDGF receptor [61]. Imatinib (Gleevec, Novartis Pharmaceuticals, East Hanover, NJ) is a 2-phenylaminopyrimidine derivative that functions as a specific inhibitor of a number of tyrosine kinase enzymes, such as insulin receptor, c-Abl (the Abelson proto-oncogene), $\mathrm{c}-\mathrm{Kit}$, and PDGF receptor. It is used in treatment of chronic myelogenous leukemia, gastrointestinal stromal tumor and other malignancies [62]. There are also some early experimental data that imatinib might have a role in the treatment of pulmonary hypertension [63], atherosclerosis, as shown in mice [64], smallpox [65], and Alzheimer's disease [66].

In TSLPtg mice the treatment with imatinib had a remarkable protective and therapeutic effect on both systemic and renal injury, resulting from significant decrease in production of cryoglobulins [61]. Imatinib treatment resulted in decrease in absolute number of antibody secreting peripheral B cells, limiting cryoglobulin production and therefore decreasing their deposition in the kidneys. The glomeruli in the treated animals showed a significant improvement of structural injury characterized by decrease in expansion of mesangial matrix, decrease in the extent of immune complex deposition with preservation of patency of capillary lumina. These changes were accompanied by an increased influx of monocyte/macrophages, indicating that at least some monocytes population some may be beneficial in amelioration of the disease. The structural changes in the glomeruli were accompanied by functional improvement including reduced proteinuria. The treatment with imatinib lead to reduction of systemic injury of CG by reduction of overall inflammatory cell infiltration in lungs and liver, and significantly improved the animal survival rate.

While the exact mechanism by which the imatinib modulates B-cell development in TSLPtg mice still remains to be elucidated, the overall effects of this study provide strong arguments that the tyrosine kinase inhibitors provide a significant benefit in patients with CG and MPGN.

\section{RAS blockade}

One of the renoprotective approaches in treatment of chronic kidney diseases is use of angiotensin-converting enzyme inhibitors (ACEI) and angiotensin II type 1 receptor blockers (ARB), both of which block the renin-angiotensin system (RAS). The beneficial effect of RAS blockade has been shown in both, experimental studies such as animal models on diabetic nephropathy, hypertension, nephrotoxicity, and in humans with diabetes, hypertension, or chronic kidney disease of different pathogenesis.

The treatment of TSLPtg mice with CG and immune complex mediated GN with enalapril (ACEI) and lorastan (ARB) resulted in significant lowering in blood pressure and proteinuria, and lead to the improvement in renal injury measured by glomerular matrix deposition and mesangial cell activation. RAS blockade also resulted in improved survival of treated animals compared with untreated controls. These effects were not observed in the group treated with hydralazine, a smooth muscle relaxant, which decreased blood pressure without other beneficial changes seen in mice treated with ACEI and ARBs. It appears from this study that RAS blockade has a renoprotective effect, which is independent from lowering the blood pressure.

\section{All-trans-retinoic acid}

Retinoids are natural derivative of vitamin A that have multiple cellular functions including induction of cell differentiation, regulation of apoptosis, and inhibition of proliferation and inflammation [67]. They act through binding and activation of retinoid nuclear receptors, including retinoid acid receptors (RARs) and retinoid $\mathrm{X}$ receptors (RXRs). In kidneys retin- 
oid receptors are present in mesangial cells, vascular smooth muscle cells and endothelial cells. Activation of these receptors leads to inhibition of expression of various factors, including TGF $\beta 1$, PDGF, endothelin-1, and nitric oxide, which are involved in pathogenesis of number of kidney diseases.

In addition to its established benefits for the treatment of acute promyelocytic leukemia, retinoic acid (RA) has been found to provide beneficial effect in multiple experimental models of kidney disease including mesangial proliferative glomerulonephritis, puromycin-induced nephrosis, lupus nephritis, diabetic nephropathy, anti-glomerular basement membrane antibody induced crescentic glomerulonephritis, and HIV-related renal disease [68-73]. Recently, it has been shown to reduce the accumulation of ECM and step down the progression of glomerulosclerosis by regulating expression of Apolipoprotein E, an important plasma protein in cholesterol homeostasis [74].

The treatment with all-trans-retinoic acid (ATRA) of TSLPtg mice unexpectedly resulted in worsening of cryoglobulinemia and deterioration of its renal and other systemic manifestations. The animals treated with ATRA developed more severe CG with increased levels of $\mathrm{IgG}$ and more inflammatory injury in lungs, liver and kidneys.

\section{Interferon- $\alpha$}

Interferon- $\alpha$ (IFN- $\alpha)$ proteins is produced by leukocytes and is mainly involved in innate immune response against viral infection. Because of its antiviral, but also antiproliferative and immune regulatory effects, it is widely used for treatment of chronic hepatitis B and C and in neoplasia. The benefit of treatment of CGGN independent of its antiviral effect has been tested using the TSLPtg model of CG. The oral administration of IFN- $\alpha$ has been chosen, although the efficacy of such route it still not established. The treatment of this model of CG resulted in only limited improvement in glomerular pathology, characterized by decreased influx of macrophages and mesangial cellularity, without significant changes in mesangial matrix accumulation. There were no significant changes in other extrarenal manifestation of cryoglobulinemia between the treated and untreated animals.

\section{Summary}

In summary, the experimental animal models of cryoglobulinemic glomerulonephritis provide an invaluable tool to study natural history of this disease, to understand pathogenesis of this type of injury, and to test novel approaches of treatment options.

\section{Cryoglobulinemic glomerulonephritis (CGGN)}

\section{Treatment - key points}

- Tyrosine kinase inhibitors (e.g. imatinib) provide a remarkable protective and therapeutic effect on both systemic and renal injury in murine cryoglobulinemia and CGGN.

- RAS blockade with ACE and ARBs has beneficial effects in experimental model of im mune complex GN by prolonging survival and improvement of kidney function and injury, which is independent from lowering the blood pressure.

- All-trans-retinoic acid results in worsening of cryoglobulinemia and deterioration of its systemic manifestations in murine model of cryoglobulinemia and CGCN.

- Oral administration of IFN-a results in limited improvement in glomerular pathology and no significant amelioration of extrarenal manifestations of cryoglobulinemia.

- Potential therapeutic target for amelioration of kidney injury in CGGN: PAI-1 and C5a.

\section{References}

1. Wintrobe MM, Buell MV. Hyperproteinemia associated with multiple myeloma: with report of a case in which an extraordinary hyperproteinemia was associated with thrombosis of the retinal veins and symptoms suggesting Raynaud's disease. Bulletin of the Johns Hopkins Hospital. 1933;52:156.

2. Lerner AB, Watson CJ. Studies of cryoglobulins; unusual purpura associated with the presence of a high concentration of cryoglobulin (cold precipitable serum globulin). Am J Med Sci. 1947;214:410.

3. Meltzer M, Franklin EC. Cryoglobulinemia - a study of twenty-nine patients. I. IgG and IgM cryoglobulins and factors affecting cryoprecipitability. Am J Med. 1966;40:828-836.

4. Meltzer M, Franklin EC, Elias K, McCluskey RT, Cooper N. Cryoglobulinemia - a clinical and laboratory study. II. Cryoglobulins with rheumatoid factor activity. Am J Med. 1966;40:837-856.

5. Johnson RJ, Gretch DR, Yamabe H et al. Membranoproliferative glomerulonephritis associated with hepatitis $\mathrm{C}$ virus infection. N Engl J Med. 1993;328:465-470.

6. Bonnet F, Pineau JJ, Taupin JL et al. Prevalence of cryoglobulinemia and serological markers of autoimmunity in human immunodeficiency virus infected individuals: a cross-sectional study of 97 patients. J Rheumatol. 2003;30:2005-2010.

7. Cicardi M, Cesana B, Del Ninno E et al. Prevalence and risk factors for the presence of serum cryoglobulins in patients with chronic hepatitis C. J Viral Hepat. 2000;7:138-143.

8. Garcia-Carrasco M, Ramos-Casals M, Cervera R et al. Cryoglobulinemia in systemic lupus erythematosus: prevalence and clinical characteristics in a series of 122 patients. Semin Arthritis Rheum. 2001;30:366-373.

9. Ramos-Casals M, Cervera R, Yague J et al. Cryoglobulinemia in primary Sjogren's syndrome: prevalence and clinical characteristics in a series of 115 patients. Semin Arthritis Rheum. 1998;28:200-205. 
10. Ramos-Casals M, Munoz S, Medina F et al. Systemic autoimmune diseases in patients with hepatitis $\mathrm{C}$ virus infection: characterization of 1020 cases (The HISPAMEC Registry). J Rheumatol. 2009;36:1442-1448.

11. Belizna CC, Hamidou MA, Levesque H, Guillevin L, Shoenfeld Y. Infection and vasculitis. Rheumatology (Oxford). 2009;48:475-482.

12. Kayali Z, Buckwold VE, Zimmerman B, Schmidt WN. Hepatitis $\mathrm{C}$, cryoglobulinemia, and cirrhosis: a meta-analysis. Hepatology. 2002;36:978-985.

13. Sansonno D, Dammacco F. Hepatitis C virus, cryoglobulinaemia, and vasculitis: immune complex relations. Lancet Infect Dis. 2005;5:227-236.

14. Tedeschi A, Barate C, Minola E, Morra E. Cryoglobulinemia. Blood Rev. 2007;21:183-200.

15. Shihabi ZK. Cryoglobulins: an important but neglected clinical test. Ann Clin Lab Sci. 2006;36:395-408.

16. Ferri C, Zignego AL, Pileri SA. Cryoglobulins. J Clin Pathol. 2002;55:4-13.

17. Brouet JC, Clauvel JP, Danon F, Klein M, Seligmann M. Biologic and clinical significance of cryoglobulins. A report of 86 cases. Am J Med. 1974;57:775-788.

18. Agnello V, Elfahal M. Cryoglobulin types and rheumatoid factors associated with clinical manifestations in patients with hepatitis C virus infection. Dig Liver Dis. 2007;39(Suppl 1):S25-31.

19. De Vita S, Soldano F, Isola M et al. Preliminary classification criteria for the cryoglobulinaemic vasculitis. Ann Rheum Dis. 2011;70:1183-1190.

20. Vernon KA, Pickering MC, Cook T. Experimental models of membranoproliferative glomerulonephritis, including dense deposit disease. Contrib Nephrol. 2011;169:198-210.

21. Friend SL, Hosier S, Nelson A, Foxworthe D, Williams DE, Farr A. A thymic stromal cell line supports in vitro development of surface $\operatorname{IgM}^{+} \mathrm{B}$ cells and produces a novel growth factor affecting B and T lineage cells. Exp Hematol. 1994;22:321-328.

22. Sims JE, Williams DE, Morrissey PJ et al. Molecular cloning and biological characterization of a novel murine lymphoid growth factor. J Exp Med. 2000;192:671-680.

23. Taneda S, Segerer S, Hudkins KL et al. Cryoglobulinemic glomerulonephritis in thymic stromal lymphopoietin transgenic mice. Am J Pathol. 2001;159:2355-2369.

24. Kowalewska J, Muhlfeld AS, Hudkins KL et al. Thymic stromal lymphopoietin transgenic mice develop cryoglobulinemia and hepatitis with similarities to human hepatitis $\mathrm{C}$ liver disease. Am J Pathol. 2007;170:981-989.

25. Gyotoku Y, Abdelmoula M, Spertini F, Izui S, Lambert PH. Cryoglobulinemia induced by monoclonal immunoglobulin $\mathrm{G}$ rheumatoid factors derived from autoimmune MRL/MpJ-lpr/lpr mice. J Immunol. 1987;138:3785-3792.

26. Kikuchi S, Pastore Y, Fossati-Jimack L et al. A transgenic mouse model of autoimmune glomerulonephritis and necrotizing arteritis associated with cryoglobulinemia. J Immunol. 2002;169:4644-4650.

27. Grey HM, Hirst JW, Cohn M. A new mouse immunoglobulin: IgG3. J Exp Med. 1971;133:289-304.

28. Nishimura Y, Nakamura H. Human monoclonal cryoimmunoglobulins. I. Molecular properties of IgG3 kappa (Jir protein) and the cryo-coprecipitability of its molecular fragments by papain. J Biochem. 1984;95:255-265.

29. Abdelmoula M, Spertini F, Shibata T et al. IgG3 is the major source of cryoglobulins in mice. J Immunol. 1989;143:526-532.

30. Quigg RJ. Complement and autoimmune glomerular diseases. Curr Dir Autoimmun. 2004;7:165-180.
31. Ravetch JV, Bolland S. IgG Fc receptors. Annu Rev Immunol. 2001;19:275-290.

32. Quigg RJ, Morgan BP, Holers VM, Adler S, Sneed AE, $3^{\text {rd, }}$ Lo CF. Complement regulation in the rat glomerulus: Crry and CD59 regulate complement in glomerular mesangial and endothelial cells. Kidney Int. 1995;48:412-421.

33. Nangaku M, Quigg RJ, Shankland SJ, Okada N, Johnson RJ, Couser WG. Overexpression of Crry protects mesangial cells from complement-mediated injury. J Am Soc Nephrol. 1997;8:223-233.

34. Bao L, Haas M, Boackle SA et al. Transgenic expression of a soluble complement inhibitor protects against renal disease and promotes survival in MRL/lpr mice. J Immunol. 2002;168:3601-3607.

35. Quigg RJ, He C, Lim A et al. Transgenic mice overexpressing the complement inhibitor crry as a soluble protein are protected from antibody-induced glomerular injury. $J$ Exp Med. 1998;188:1321-1331.

36. Schiller B, Cunningham PN, Alexander JJ, Bao L, Holers VM, Quigg RJ. Expression of a soluble complement inhibitor protects transgenic mice from antibody-induced acute renal failure. J Am Soc Nephrol. 2001;12:71-9.

37. Muhlfeld AS, Segerer S, Hudkins K et al. Overexpression of complement inhibitor Crry does not prevent cryoglobulinassociated membranoproliferative glomerulonephritis. Kidney Int. 2004;65:1214-1223.

38. Trendelenburg M, Fossati-Jimack L, Cortes-Hernandez J, et al. The role of complement in cryoglobulin-induced immune complex glomerulonephritis. I Immunol. 2005;175: 6909-6914.

39. Nimmerjahn F, Ravetch JV. Fcgamma receptors: old friends and new family members. Immunity. 2006;24:19-28.

40. Muhlfeld AS, Segerer S, Hudkins K et al. Deletion of the fcgamma receptor IIb in thymic stromal lymphopoietin transgenic mice aggravates membranoproliferative glomerulonephritis. Am J Pathol. 2003;163:1127-1136.

41. Guo S, Muhlfeld AS, Wietecha TA et al. Deletion of activating Fcgamma receptors does not confer protection in murine cryoglobulinemia-associated membranoproliferative glomerulonephritis. Am J Pathol. 2009;175:107-118.

42. Floege J, Burns MW, Alpers CE et al. Glomerular cell proliferation and PDGF expression precede glomerulosclerosis in the remnant kidney model. Kidney Int. 1992;41:297-309.

43. Johnson RJ, Raines EW, Floege J et al. Inhibition of mesangial cell proliferation and matrix expansion in glomerulonephritis in the rat by antibody to platelet-derived growth factor. J Exp Med. 1992;175:1413-1416.

44. Floege J, Topley N, Resch K. Regulation of mesangial cell proliferation. Am J Kidney Dis. 1991;17:673-676.

45. Okuda S, Languino LR, Ruoslahti E, Border WA. Elevated expression of transforming growth factor-beta and proteoglycan production in experimental glomerulonephritis. Possible role in expansion of the mesangial extracellular matrix. JClin Invest. 1990;86:453-462.

46. Yamamoto T, Nakamura T, Noble NA, RuoslahtiE, Border WA. Expression of transforming growth factor beta is elevated in human and experimental diabetic nephropathy. Proc Natl Acad Sci USA. 1993;90:1814-1818.

47. van Roeyen CR, Eitner F, Boor P et al. Induction of progressive glomerulonephritis by podocyte-specific overexpression of platelet-derived growth factor-D. Kidney Int. 2011.

48. Taneda S, Hudkins KL, Cui Y, Farr AG, Alpers CE, Segerer S. Growth factor expression in a murine model of cryoglobulinemia. Kidney Int. 2003;63:576-590. 
49. Eddy AA. Plasminogen activator inhibitor-1 and the kidney. Am J Physiol Renal Physiol. 2002;283:F209-F220.

50. Fogo AB. Renal fibrosis: not just PAI-1 in the sky. J Clin Invest. 2003;112:326-328.

51. Huang Y, Noble N. An unexpected role of plasminogen activator inhibitor-type 1 (PAI-1) in renal fibrosis. Kidney Int. 2005;67:2502-2503.

52. Malliaros J, Holdsworth SR, Wojta J, Erlich J, Tipping PG. Glomerular fibrinolytic activity in anti-GBM glomerulonephritis in rabbits. Kidney Int. 1993;44:557-564.

53. Matsuo S, Lopez-Guisa JM, Cai X et al. Multifunctionality of PAI-1 in fibrogenesis: evidence from obstructive nephropathy in PAI-1-overexpressing mice. Kidney Int. 2005;67:2221-2238.

54. Oda T, Jung YO, Kim HS et al. PAI-1 deficiency attenuates the fibrogenic response to ureteral obstruction. Kidney Int. 2001;60:587-596.

55. Moll S, Schaeren-Wiemers N, Wohlwend A et al. Protease nexin 1 in the murine kidney: glomerular localization and up-regulation in glomerulopathies. Kidney Int. 1996;50: 1936-1945.

56. Taneda S, Hudkins KL, Muhlfeld AS et al. Protease nexin-1, tPA, and PAI-1 are upregulated in cryoglobulinemic membranoproliferative glomerulonephritis. J Am Soc Nephrol. 2008;19:243-251.

57. Duffield JS. The inflammatory macrophage: a story of Jekyll and Hyde. Clin Sci (Lond). 2003;104:27-38.

58. Gordon S. The macrophage: past, present and future. Eur J Immunol. 2007;37(Suppl 1):S9-S17.

59. Duffield JS, Tipping PG, Kipari T et al. Conditional ablation of macrophages halts progression of crescentic glomerulonephritis. Am J Pathol. 2005;167:1207-1219.

60. Guo S, Wietecha TA, Hudkins KL et al. Macrophages are essential contributors to kidney injury in murine cryoglobulinemic membranoproliferative glomerulonephritis. Kidney Int. 2011.

61. Iyoda M, Hudkins KL, Becker-Herman S et al. Imatinib suppresses cryoglobulinemia and secondary membranoproliferative glomerulonephritis. J Am Soc Nephrol. 2009;20: $68-77$.
62. Druker BJ. Imatinib as a paradigm of targeted therapies. Adv Cancer Res. 2004;91:1-30.

63. Tapper EB, Knowles D, Heffron T, Lawrence EC, Csete M. Portopulmonary hypertension: imatinib as a novel treatment and the Emory experience with this condition. Transplant Proc. 2009;41:1969-1971.

64. Lassila M, Allen TJ, Cao Z et al. Imatinib attenuates diabetes-associated atherosclerosis. Arterioscler Thromb Vasc Biol. 2004;24:935-942.

65. Reeves PM, Bommarius B, Lebeis $\mathrm{S}$ et al. Disabling poxvirus pathogenesis by inhibition of Abl-family tyrosine kinases. Nat Med. 2005;11:731-739.

66. He G, Luo W, Li P et al. Gamma-secretase activating protein is a therapeutic target for Alzheimer's disease. Nature. 2010;467:95-98.

67. Evans TR, Kaye SB. Retinoids: present role and future potential. Br J Cancer. 1999;80:1-8.

68. Lehrke I, Schaier M, Schade K et al. Retinoid receptor-specific agonists alleviate experimental glomerulonephritis. Am J Physiol Renal Physiol. 2002;282:F741-51.

69. Wagner J, Dechow C, Morath $\mathrm{C}$ et al. Retinoic acid reduces glomerular injury in a rat model of glomerular damage. $\mathrm{J} \mathrm{Am}$ Soc Nephrol. 2000;11:1479-1487.

70. Suzuki A, Ito T, Imai E et al. Retinoids regulate the repairing process of the podocytes in puromycin aminonucleoside-induced nephrotic rats. J Am Soc Nephrol. 2003;14:981-991.

71. Perez de Lema G, Lucio-Cazana FJ, Molina A et al. Retinoic acid treatment protects MRL/lpr lupus mice from the development of glomerular disease. Kidney Int. 2004;66:1018-1028.

72. Han SY, So GA, Jee YH et al. Effect of retinoic acid in experimental diabetic nephropathy. Immunol Cell Biol. 2004;82:568-576.

73. Ratnam KK, Feng X, Chuang PY et al. Role of the retinoic acid receptor-alpha in HIV-associated nephropathy. Kidney Int. 2011;79:624-634.

74. Zhou TB, Qin YH, Lei FY, Su LN, Zhao YJ, Huang WF. All-trans retinoic acid regulates the expression of apolipoprotein $\mathrm{E}$ in rats with glomerulosclerosis induced by Adriamycin. Exp Mol Pathol. 2011;90:287-294.

Submitted: 28 September, 2011

Accepted after reviews: 14 October, 2011 